\title{
Smarthome Automatic Lighting Berbasis Web
}

\author{
Ryan Afilusuf ${ }^{1}$, Fitri Marisa ${ }^{2}$, Indra Dharma Wijaya ${ }^{3}$
}

\begin{abstract}
In this study, main purpose is to design a Web based Smarthome automatic lighting as a replacement buttons or switches, but "Online"web based. data communication protocol used in this study is Mikrokontoller Arduino Uno specially designed to be integrated with the Website. This equipment can be used to control the lights from a distance without having to press the switch confessional. So, it can help the user to control and command scheduling ON / OFF lighting's home using the web.
\end{abstract}

Intisari-Dalam penelitian ini tujuan utama adalah untuk merancang sebuah Aplikasi Pengendali lampu rumah via website sebagai pengganti tombol atau saklar namun berbasis web "Online". Adapun protokol komunikasi data yang digunakan dalam penelitian ini ialah Mikrokontoller Arduino Uno yang dirancang khusus agar dapat terintegrasi dengan Website. peralatan ini dapat digunakan untuk mengendalikan lampu dari jarak jauh tanpa harus menekan saklar konfensional. sehingga dapat membantu pemakai untuk mengendalikan dan melakukan perintah penjadwalan ON/OFF Berdasarkan Jam lampu listrik di rumah dari jarak jauh menggunakan web.

Kata Kunci-Smarthome, Home Automation, Arduino Uno, Automatic LightingBerbasis Web

\section{PENDAHULUAN}

Di era digital saat ini perkembangan teknologi terus dilakukan dan di kembangkan untuk membantu manusia dalam meringankan pekerjaan maupun membantu manusia mempermudah menyelesaikan pekerjaan nya, semua teknologi dikembangkan tanpa mengesampingkan faktor lingkungan yang nantinya diharapkan juga ramah lingkungan. Terlepas dari hal tersebut saat ini teknologi dari para pengembang telah di tujukan pada penghematan sumber daya alam dimana semakin hari sumber daya alam di bumi semakin besar yang digunakan, seperti hal nya kebutuhan energi listrik nasional semakin hari semakin meningkat, peningkatan tersebut disebabkan oleh pemeakaian energi listrik industri,pabrik maupun pemakaian listrik pribadi, selain itu kebiasaan pola hidup masyarakat akan borosnya penggunaan listrik juga menjadi salah satu faktor pemborosan energi listrik.

Untuk itu diperlukan adanya sebuah solusi dalam menghemat penggunaan energi listrik tanpa mengurangi kebutuhan listrik pada saat yang diperlukan oleh masyarakat. salah satu solusi penghematan sumber daya listrik yang dikembangkan dengan memanfaatkan teknologi internet maka terciptalah aplikasi yang bisa dipergunakan untuk penghematan listrik dimana aplikasi ini akan membantu kita dalam pengontrolan lampu pada rumah dengan jarak jauh karena sampai saat ini pengontrolan lampu masih menggunakan cara lama yaitu saklar manual sehingga hal ini sangat tidak efisien dan untuk menghidupkan atau mematikan lampu harus menekan saklar tersebut.

\footnotetext{
${ }^{1}$ Mahasiswa, Universitas Widyagama, jln.Borobudur 35 Malang 65128 INDONESIA(telp: 082234006726 e-mail afilusuf@gmail.com)

${ }^{23}$ Dosen, Jurusan Teknik Informatika Fakultas Teknik Universitas Widyagama, jln.Borobudur 35 Malang 65128 INDONESIA (e-mail :fitrimarisa@widyagama.ac.id)
}

Berdasarkan dari penelitian sebelumnya, penggunaan Bluetooth sebagai sistem kontrol lampu rumah saat ini sudah tidak efisien lagi, dimana saat ini sudah banyak tersedia jaringan internet yang akan lebih efisien karena jarak akses yang tak terbatas seperti hal nya Bluetooth serta penggunaan platform website yang dapat di akses menggunakan semua sistem operasi.

Dari latar belakang yang telah dikemukakan, didapatkan masalah sebagai berikut .

Bagaimana membangung sebuah sistem kontrol lampu rumah berbasis web sehingga memudahkan pengguna untuk mengontrol lampu via website. Serta Bagaimana membuat sistem aplikasi kontrol lampu rumah dengan pemanfaatan media komunikasi agar bisa di akses secara jarak jauh. Selanjutnya ialah Bagaimana merancang Hardware sehingga bisa terkoneksi dengan website untuk mengontrol lampu jarak jauh.

Adapun ruang lingkup penelitian sebagai batasan masalah dalam penelitian ini adalah sebagai berikut :

- Sistem kontrol hanya untuk mengontol lampu tidak untuk perangkat listrik lainnya.

- Peralatan listrik yang digunakan sebagai obyek dalam percobaan ini hanya digunakan untuk Lampu rumah dengan 5Watt $150-250 \mathrm{~V} \quad 50 / 60 \mathrm{~Hz} 4$ Channel untuk mengontrol 4 Lampu

- Sistem akan dibuat menggunakan Integrasi website dengan hardware Arduino Uno,Ethernet Shield dan relay

- Sistem kontrol pada penelitian ini hanya meliputi mematikan dan menghidupkan lampu secara manual di website dan Auto set timer berdasarkan jam.

- Dalam aplikasi ini penjadwalan hanya berdasarkan jam, belum menggunakan panjadwalan berdasarkan tanggal

- Notifikasi penggunaan lampu dan koneksi menggunakan Serial monitor

\section{LANDASAN TEORI}

\section{A. Smarthome (Rumah Pintar)}

Smarthome adalah sebuah bangunan yang dilengkapi dengan sistem elektronik yang memungkinkan penghuninya untuk menggunakan dan mengendalikan berbagai perangkat elektronik dengan memasukkan perintah sederhana. Perangkat tersebut juga dapat berkomunikasi satu sama lain, misalnya remote termometer terletak di suatu tempat untuk memberikan data sistem pemanas, ventilasi, dan penyejuk udara (HVAC =heating, ventilating, air conditioning) di ruangan yang berbeda dan perangkat penggerak bereaksi terhadap satu set perintah berbeda yang dikirimkan oleh unit kontrol atau perangkat lain yang biasanya ditemukan dalam sistem kontrol terdistribusi.

Sistem elektronik biasanya terdiri dari perangkat elektronik penyedia data (sensor), perangkat penafsir kontrol data (actuators), perangkat pengendali (central units) dan perangkat 
penyedia komunikasi antarmuka untuk sistem (gateways). Semua perangkat ini biasanya ditempatkan di lokasi yang berbeda dari bangunan sesuai dengan kebutuhan untuk memungkinkan tingkat sederhana, data rendah, namun kuat komunikasi antar perangkat.[4].

\section{B. Website}

Website adalah salah satu aplikasi yang berisikan dokumen-dokumen multimedia (teks, gambar, suara, animasi, video) didalamnya yang menggunakan protokol HTTP (hyper text transfer protocol ) dan untuk mengaksesnya mengunakan perangkat lunak yang disebut browser. Beberapa jenis browser yang populer saat ini di antaranya : Internet Exspoler yang diperoduksi oleh Microsoft, Mozila Firefox, Opera dan Safari yang diperoduksi oleh Aplle.

Browser (perambah) adalah aplikasi yang mampu menjalankan dokumen-dokumen web dengan cara diterjemahkan. Prosesnya dilakukan oleh komponen yang terdapat didalam aplikasi browser yang biasa disebut web engine. Semua dokumen web ditampilkan dengan cara diterjemahkan.[3]

\section{Arduino}

Arduino adalah sebuah produk design sistem minimum mikrokontroler yang di buka secara bebas. arduino menggunakan bahasa pemrograman $\mathrm{C}$ yang telah dimodifikasi dan sudah ditanamkan rogrammer bootloader yang berfungsi untuk menyembatani antara software compiler arduino dengan mikrokontroler.[5]

Bahasa Arduino diimplementasi dari $\mathrm{C} / \mathrm{C}++$ dalam pengkabelan. Ketika kita membuat sketsa program Arduino, secara tidak langsung kita membuat library pengkabelan yang sudah ada dalam Arduino IDE. Hal tersebut yang bisa membuat kita menciptakan program yang berjalan hanya dengan menggunakan dua fungsi yaitu: setup() dan loop() . Bahasa pengkabelan terisnpirasi dari bahasa Processing dan struktur program Arduino diturunkan dari bahasa Processing dimana terdapat dua fungsi pembuat program yaitu setup() dan $\operatorname{draw}() \cdot[2]$

\section{Ethernet Shiled}

Arduino Ethernet Shield adalah modul yang berfungsi menghubungkan Arduino board dengan jaringan internet,karna itu berdasar pada Wiznet W5100 ethernet chip. Ethernet Shield menambah kemampuan arduino board agar terhubung ke jaringan komputer. Ethernet shield berbasiskan cip ethernet Wiznet W5100. Ethernet library digunakan dalam menulis program agar arduino board dapat terhubung ke jaringan dengan menggunakan arduino ethernet shield.[1]

\section{ANALISIS DAN PERANCANGAN SISTEM}

\section{A. Gambaran Umum Program}

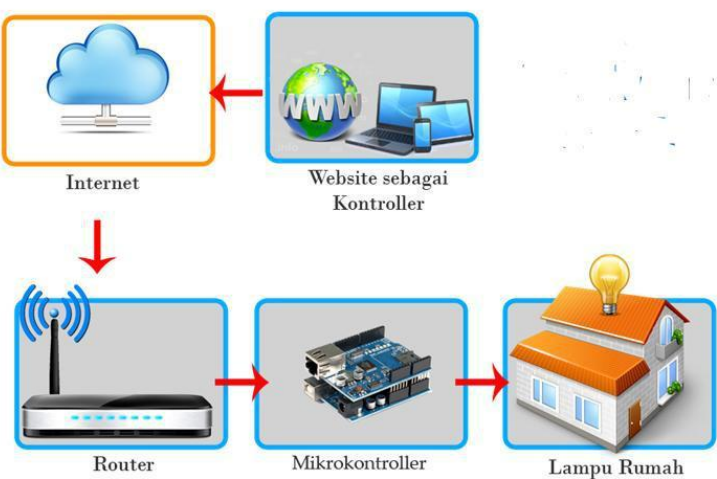

Gbr.1 Gambaran umum program

Pada Gambar di atas merupakan gambaran umum alur program aplikasi ini dimana ada 5 fase umum yang merupakan tahapan-tahapan jalannya program. Pertama yaitu website sebagai media kontrol perangkat yang dijembatani oleh koneksi internet dan selanjuutnya di tangkap oleh router selanjutnya menuju ke box mikrokontroller dan diteruskan ke masing-masing lampu pada terminal box kontroller yang telah di sediakan.

\section{B. Data Flow Diagram (DFD)}

Data Flow Diagram atau disingkat DFD merupakan suatu penggambaran model yang memungkinkan profesional sistem untuk menggambarkan sistem sebagai suatu susunan proses yang dihubungkan satu sama lain dengan alur data, baik secara manual maupun terkomputerisasi.[6]

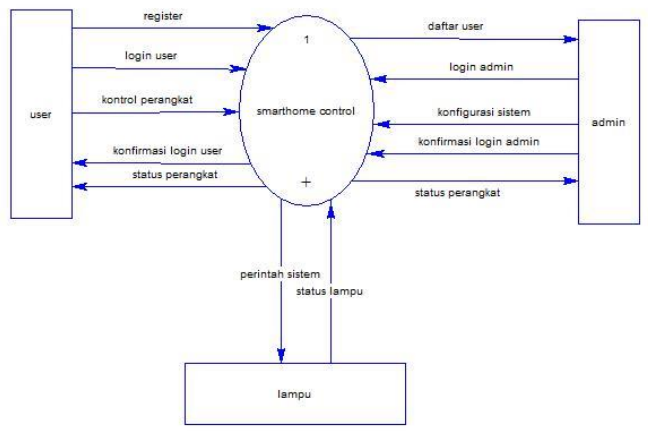

Gbr2. DFD Level 0

Pada diagram konteks di atas sistem ini memiliki tiga entitas utama yaitu admin sebagai pengelola sistem, user atau pengguna dan lampu sebagai objek yang menerima perintah dari sistem.

Pada gambar terlihat user melakukan register,lalu login dengan akun dan mengkonfigurasi perangkat pada proses smarthome control yang semua datanya tersimpan did an bias di konfirmasi oleh admin, selaanjutnya perintah system dari user maupun admin akan dip roses ke masing-masing lampu. 


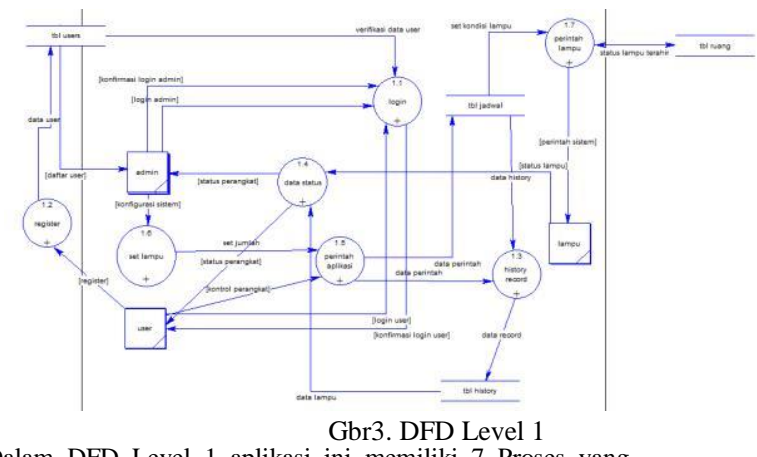

Dalam DFD Level 1 aplikasi ini memiliki 7 Proses yang

saling berinteraksi, berikut penjelasannya :

- Proses 1.1 dalam proses ini admin atau pemilik aplikasi menginput data login yang nantinya berfungsi sebagai login kontrol panel untuk manage user dan edit database user sesuai kebutuhan yang diperlukan

- Proses 1.2 Proses ini merupakan proses registrasi user untuk melengkapi form register yang nantinya akan masuk kedalam database user dan digunakan untuk proses login aplikasi dan verifikasi login aplikasi

- Proses 1.3 dalam tahapan proses ini semua tentang hubungan antar database dan perintah aplikasi dari admin maupun user, beda data perintah antara admin dan user ialah jika admin dalam proses ini melakukan data perintah pada aplikasi untuk menyiapkan atau set database sesuai kebutuhan user (misal : jumlah lampu) sedangkan pada user ialah data perintah kontrol lampu yang nanti masingmasing akan di simpan pada database tbl jadwal untuk perintah timer atau jadwal lampu dan semua proses akan di catat dalam database history

- Proses 1.4 Proses data status ialah proses dimana lampu atau perangkat mengirimkan data pada admin maupun user dimana pada proses ini jika lampu dalam keadaan mati maka perangkat akan mengirimkan status pada aplikasi sesuai dengan kondisi yang ada yaitu mati, dan sebaliknya

- Proses 1.5 Semua perintah baik dari user maupun admin sesuai dengan perintah masing-masing akan diproses dan diteruskan ke database selanjutnya akan di teruskan perintah tersebut ke lampu

- Proses 1.6 Admin membuat konfigurasi pada database sesuai kebutuhan user meliputi jumlah lampu yang akan di buat sesuai kebutuhan user

- Proses 1.7 Perintah dalam meng eksekusi lampu dari sistem akan dilanjutkan pada masing-masing lampu, dalam proses ini status lampu terakhir akan di catat di database ruang, database ini berfungsi sebagai record status terbaru yang akan di tampilkan pada aplikasi, sehingga user mengetahui status terakhir mereka melakukan penjadwalan lampu.

\section{Entity Relationship Diagram (ERD)}

Transformasi ERD ke dalam Database Relational

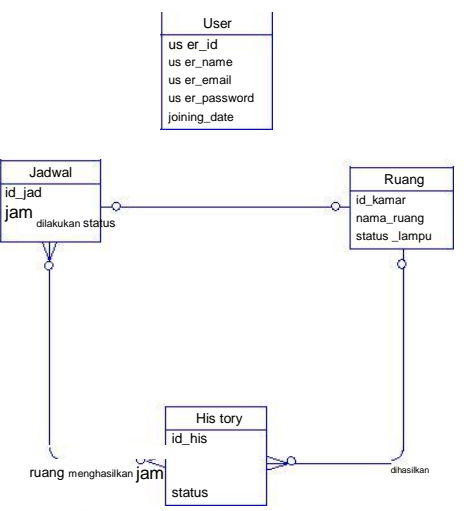

Gbr.4 Relasi Antar Tabel Data Base CDM Model

Dalam database system aplikasi ini terdapat 4 tabel diantaranya adalah table user yaitu table yang menyimpan data user yang telah melakukan regsitrasi pada sistem. Berikutnya ialah table jadwal dan ruang dalam table jadwal ialah table yang khusus menerima perintah jadwal dari system dan table ruang ialah table yang khusus merekap perintah terharir system berdasarkan ruang dan status terahir lampu. Kedua table tersebut selanjutnya menuju table history dan fungsi dari table ini ialah mencatat atau merekap semua aktifitas user menjadi sebuah history record.

\section{IMPLEMENTASI}

Setelah melakukan perancangan dan pengujian terhadap sistem meliputi koneksi software dan hardware maka selanjutnya yang harus dilakukan adalah mengimplementasikan aplikasi website terhadap kontroller lampu secara langsung. Dalam bab ini akan membahas bagaimana implementasi aplikasinya.

\section{A. Panduan Implementasi system}

Terlepas dari penelitian ini dalam mengimplementasikan sistem ini terdapat beberapa tahap yang harus di siapkan oleh admin sebagai pennyedia aplikasi ini dikarenakan kebutuhan user yang berbeda mengenai jumlah lampu/device yang akan mereka kontrol berikut adalah langkah-langkah yang harus di siapkan oleh admin.

Dalam aplikasi ini Relay yang digunakan sesuai jumlah lampu yang di inginkan maksimal relay 10 channel untuk mengontrol 10 Lampu. Lalu Setelah relay dan Arduino Ethernet shield dirakit maka selanjutnya admin akan menyediakan database sesuai dengan kebutuhan user. Berikutnya melakukan compiler program pada Arduino serta mencoba koneksi antara Arduino dan website. Selanjutnya admin akan mendesain website berikut tombol dan form jadwal sesuai dengan kebutuhan user. Setelah website dan hardware selesai maka selanjutnya tes koneksi dan tes perintah apakah Aplikasi tersebut bejalan atau tidak.

Implementasi interface menggambarkan tampilan dari aplikasi yang dibangun yaitu implementasi interface sistem smarthome automatic lighting berbasis web. Berikut ini adalah implementasi antar muka dari aplikasi yang dibuat : 


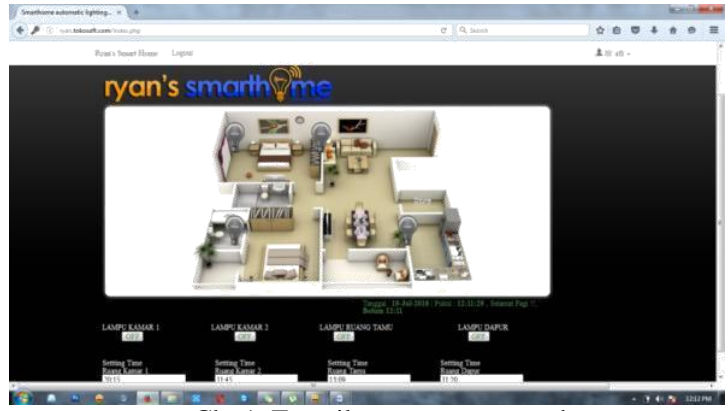

Gbr.1. Tampilan menu utama web

Pada menu ini user atau member dapat mengontrol lampu sesuai dengan rumah mereka dimana di setiap tombol telah tertera nama ruangan dan ada miniature gambar sesuai dengan rumah member tersebut sehingga memudahkan mereka dalam melakukan pengontrolan lampu dengan benar.

\section{B. Tampilan Hardware}

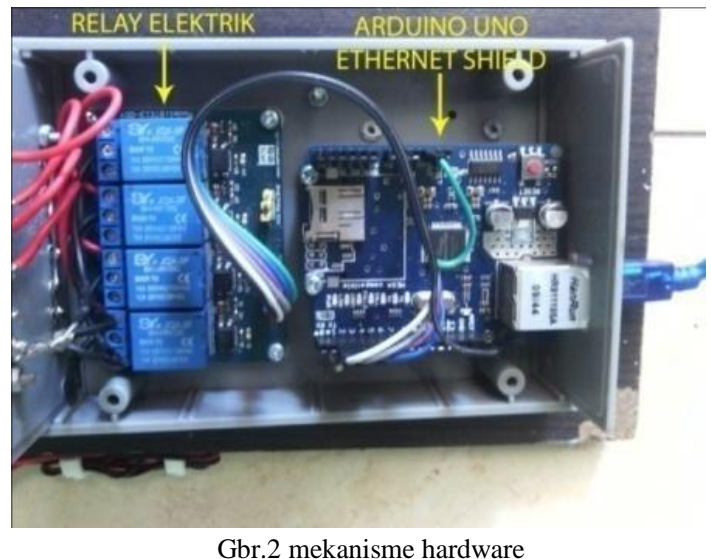

Ini merupakan tampilan box kontroller smarthome automatic lighting berbasis web, Pada gambar 4.4 merupakan isi dari box kontroller pada bos tersebut terdapat relay elektrik yang berguna sebagai saklar elektrik otomatis untuk mematikan serta menghidupkan lampu secara otomatis sesuai dengan perintah yang diberikan mikrokontroller.

\section{Cara kerja Program}

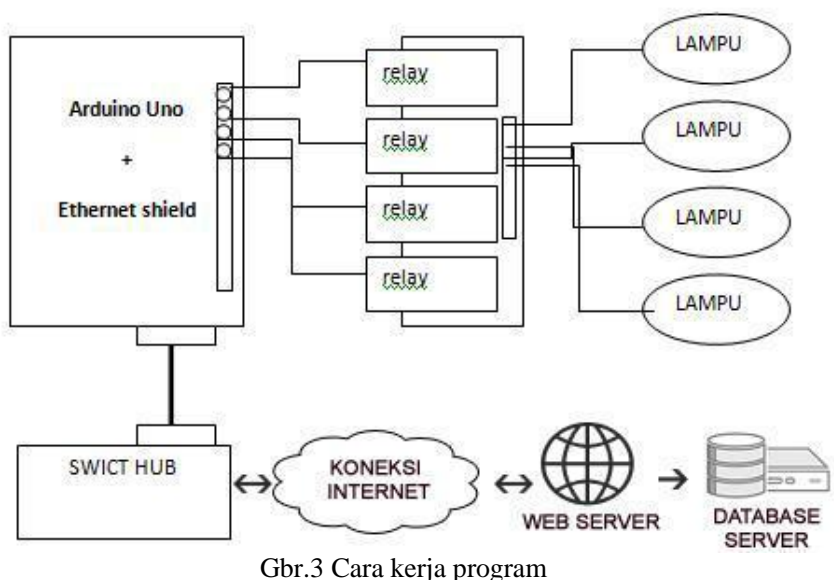

Pada hardware disini bermula dari lampu, masing-masing Lampu LED 5Watt $150-250 \mathrm{~V} 50 / 60 \mathrm{~Hz}$ akan tersambung dengan masing-masing terminal yang ada di relay, selanjutnya relay akan tersambung pada arduino Uno \& Ethernet shield melalui Pin yang tersedia pada Mikrokontoller, disini penyusun menggunakan PIN Nomor 2,3,4,5 PIN 3A dan PIN GND.Selanjutnya mikrokontroller dan ethernetshield akan terhubung dengan switch hub melalui kabel UTP LAN dan tujuannya ialah agar hardware ini terkoneksi dengan internet yang selanjutnya akan terkoneksi dengan website kontroller.

\section{Setting Koneksi mikrokontroller dan website}

Sebelum Menjalankan aplikasi ini user harus melakukan setting pada mikrokontroler arduino uno agar terkoneksi dengan jaringan internet di tempat tersebut. Berikut penjelasan nya :

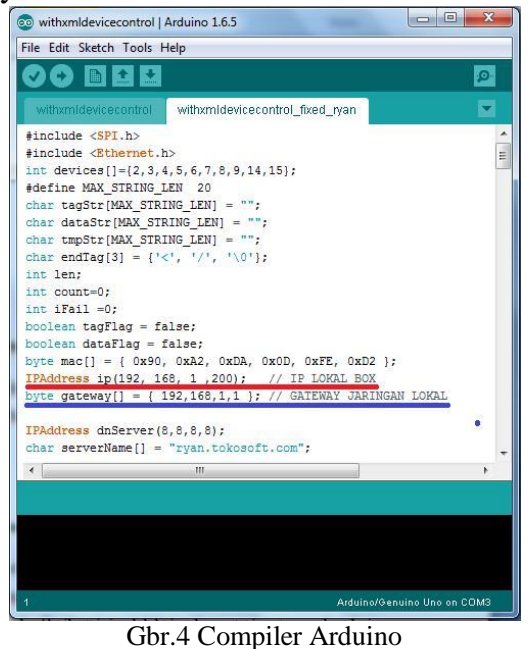

Sebelum menjalankan aplikasi hal pertama yang dilakukan adalah setting koneksi antar hardware dengan jaringan internet di tempat tersebut agar hardware dapat terkoneksi langsung dengan website. Setting dilakukan pada aplikasi arduino uno atau yang sering disebut dengan compiler arduino.

Agar hardware dapat terkoneksi langsung dengan jaringan internet maka dilakukan perubahan Gateway IP sesuai dengan tempat tersebut. Pada gambar 4 garis biru byte Gateway adalah 192.168.1.1 dan garis merah merupakan IP Box mikrokontroller tersebut dimana mengikuti IP gateway yang ada yaitu 192.168.1.200.
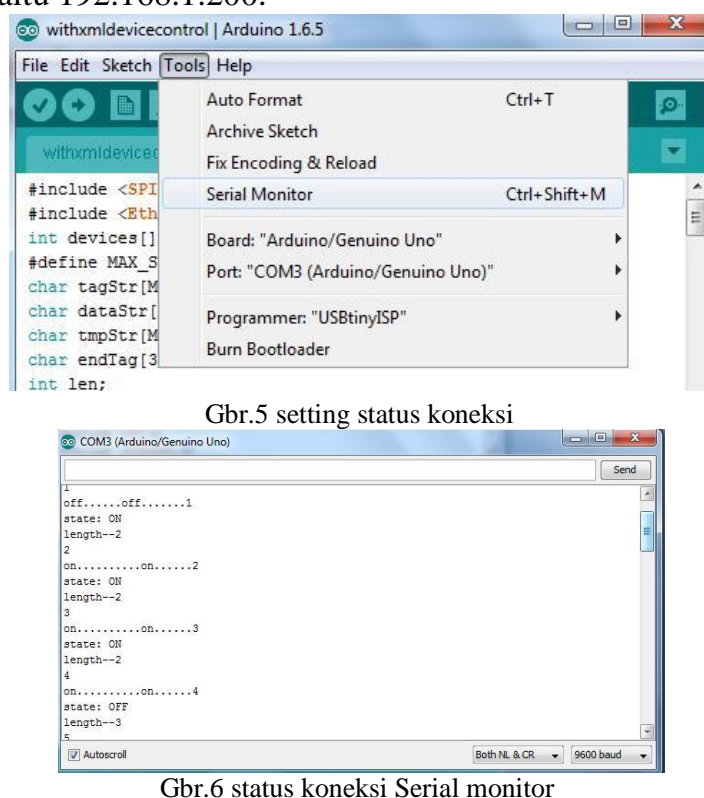

Untuk mengetahui status koneksi antara hardware dan website ialah dengan cara membukan menu tolls pada 
compiler arduino lalu pilih serial monitor, pada menu ini akan diketahui apakah perangkat tersebut terkoneksi atau tidak dengan website, serta aka nada status lampu yang hidup maupun yang mati. Pada gambar 6 merupakan tampilan serial monitor dimana ada empat lampu yang memiliki status berbeda seperti di gambar.

\section{E. Uji Coba aplikasi}

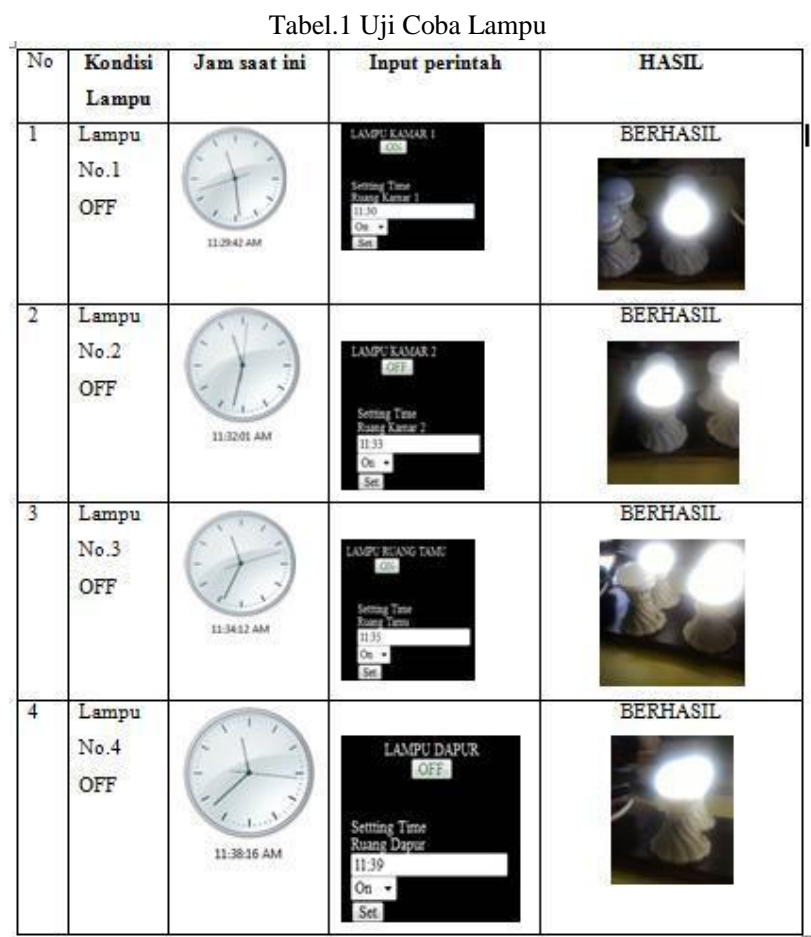

Pada table di atas merupaka table uji coba lampu tahap ini dilakukan uji coba penjadwalan lampu atau schedule, pada percobaan ini masing-masing lampu akan di uji coba dengan perintah menghidupkan di jam atau menit tertentu misal : Kondisi lampu OFF di jam 11:23 dan akan diberi perintah ON pada jam 11:24

\section{KESIMPULAN DAN SARAN}

Dari pembahasan implementasi sistem aplikasi smarthome automatic lighting berbasis web adalah :

- Mempermudah pengontrolan lampu rumah secara real time dimana saja dan kapan saja

- Penelitian ini merupakan hasil pengembangan dari penelitian sebelumnya dimana menggunakan Bluetooth belum bisa mengontrol lampu secara jarak jauh sedangkan dengan aplikasi ini pengontrolan lampu dapat dilakukan dengan jarak jauh.

- Penggunaan website sebagai sarana akses aplikasi smarthome memiliki kelebihan dibandingkan menggunakan aplikasi android (APK) karena dapat di akses dengan multi platform baik menggunakan Android, Linux maupun IOS website ini dapat di akses.

Adapun saran dari penyusun skripsi diharapkan dapat melakukan pengembangan selanjutnya adalah :

- Aplikasi smarthome ini dapat di implementasikan pada rumah, toko dalam skala kecil. Namun untuk perkantoran atau perusahaan dalam skala besar masih perlu pengujian ulang tentang ketahanan dan perlu rangkaian ulang dalam menyesuaikan kebutuhan voltase listrik agar sesuai dengan kebutuhan di lapangan.

- Jika ingin mengimplementasikan alat ini pada rumah harap diperhatikan aspek penting seperti kekuatan arus dan tegangan perangkat yang akan di kontrol.

- Untuk penelitian kedepan nya dapat dikembangkan untuk mengontrol segala macam barang elektronik rumah tangga yang tentunya pada sisi hardware juga harus di modifikasi sesuai dengan kebutuhan perangkat tersebut.

- Aplikasi ini masih berjalan dengan sistem foreground yaitu aplikasi yang berjalan ketika kita menjalankannya atau membuka webnya, diharapkan untuk penelitian selanjutnya aplikasi ini dapat dikembangkan menjadi aplikasi Background yaitu aplikasi yang berjalan bersama sistem yang akan terus berjalan walaupun tidak membuka website, sehingga pada saat melakukan schedule lampu tidak perlu lagi membiarkan website tetap terbuka.

- Saran untuk penelitian berikutnya agar menyediakan menu notitikasi status koneksi antara website dan hardware agar user dapet mengetahui status dari device atau perangkat mereka.

\section{REFERENSI}

[1] Arduino.cc. (2015). Arduino Ethernet Shield. Retrieved fromhttps://www.arduino.cc:

https://www.arduino.cc/en/Main/ArduinoEthernetShield

[2] Iyuditya, E. D. (2013). SISTEM PENGENDALI LAMPU RUANGAN SECARA OTOMATIS MENGGUNAKAN PC BERBASIS MIKROKONTROLER ARDUINO UNO.

[3] M.Rudyanto, A. (2011). Pemograman Web Dinamis Menggunakan PHP dan MySQL. yogyakarta: Andi Publisher .

[4] Oktaviani, T. W. (2014). Perancangan User Interface Berbasis Web untuk Home. JNTETI, Vol. 03, No. 03, Agustus 2014, 2.

[5] Vidy Masinambow, M. E. (2014). Pengendali Saklar Listrik Melalui Ponsel Pintar Android. e-journal Teknik Elektro dan Komputer (2014), ISSN 2301 -8402,

[6] Khalid, M. U. (2011). Perancangan sistem informasi perpustakaan. Sistem Informasi S1, V. 